\title{
Adsolubilization of Organic Dye through Surfactant Modified Silica Gel Waste from Aquatic Environment: Batch and Fixed Bed Studies
}

\author{
(Wastewater Treatment)
}

\author{
Suman Koner and Asok Adak*
}

\begin{abstract}
The adsolubilization of organic dye (Methylene blue, MB) was studied in both batch and continuous mode using silica gel waste (SGW) after modification of its surface by surfactant, to be called as surfactant modified silica gel waste (SMSGW). In batch mode, the kinetic study, dose study and effect of different interfering substances were conducted. In continuous mode, the SMSGW packed column was analysed by logit model. The equilibrium contact time and optimum adsorbent dose were found out to be 45 minutes and $8 \mathrm{~g} / \mathrm{L}$ respectively for an initial MB concentration of $100 \mathrm{mg} / \mathrm{L}$. From column study, the values of adsorption rate constant $(K)$ and adsorption capacity constant $\left(N_{o}\right)$ were obtained as $0.018063 \mathrm{~L} / \mathrm{mg} . \mathrm{h}$ and $20501 \mathrm{mg} / \mathrm{L}$ respectively. The SMSGW was efficiently regenerated by rectified spirit. From the studies, SMSGW was found to be an efficient adsorbing media for dye removal.
\end{abstract}

Keywords - Adsolubilization, Dye, Surfactant modified silica gel, Wastewater

\section{Introduction}

Methylene blue (MB) is a well-known hazardous dye being used for various purposes: a biological stain, a dermatological agent, a veterinary medicine, an additive to poultry feed to inhibit propagation of mold, intestinal parasites and fungus etc. It is also extensively used in textile, dying and paper printing industries. It is a mutagen and mitotic poison. It may cause irritation in eye, skin and digestive track. Therefore, it is necessary to remove this dye from contaminated water before its discharge to environment. Various treatment technologies that are available for the removal of it from wastewater include

Dr. Suman Koner

Jalpaiguri Government Engineering College, Jalpaiguri, West Bengal India

\section{Dr. Asok Adak}

Indian Institute of Engineering Science and Technology Shibpur India

Phone: +91-33-26684561 (Extn. 713); Fax: +91-33-26682916

* Corresponding author adsorption [1], photodegradation [2], electrocoagulation [3], advanced oxidation [4], biological process [5] etc.

Many of the above mentioned processes are not costeffective and hence are not suitable for being applied in developing countries. Further dye recovery is not possible from application of most of the above techniques. Very recently removal of organic contaminants using surfactant modified solid surface (e.g. metal oxide) has drawn much attention. The surface of the metal oxides can be modified by surfactant to form micelle like structures having potential to solubilize organic molecules within the structures formed. These micelles are called hemimicelles or admicelles and the phenomenon is called Adsolubilization. For the last two decades this new separation technology has been used for the removal of different organic compounds [6-8]. Most of the studies mentioned above have been conducted in only batch mode. Reports regarding the engineering application of adsolubilization for wastewater treatment in both batch and continuous mode are only a few. Thus, the present study aims towards the removal and recovery of MB dye from wastewater by quaternary ammonium based cationic surfactant (CS) (e.g. cetyltrimethylammonium bromide) treated silica gel waste in both batch and continuous mode. The effect of adsorbent dose, contact time, interfering substances, operating conditions have been studied in details for the treatment of highly concentrated dye bearing wastewater. Fixed bed column study has been conducted and the results were analysed using logit model and the field design parameters have been calculated.

\section{Materials and Methods}

\section{A. Reagents}

Orange II, cetyltrimethylammonium bromide (CTAB)(HiMedia, India), methylene blue (MB) and Chloroform (Merck, India) were used as received. All other chemicals used in this study were of high purity and used without further purification. All the chemicals were of Analytical Reagent Grade. 


\section{B. Preparation of Surfactant-Modified Silica Gel waste (SMSGW)}

SGW was collected from solid waste generated from a local silica gel factory located at Kolkata, India (Kalpataru Pvt. Ltd., Kolkata). After collection, the material was thoroughly washed with tap water followed by distilled water, dried at $100^{\circ} \mathrm{C}$ and then sieved. About $70 \%$ of the total material lies in the particle size between 150 - 300 microns and that was used for the study. The zero point charge of SGW was reported to be 2.0.

For preparation of SMSGW, $180 \mathrm{~g} \mathrm{SGW}$ (at a dose of 30 $\mathrm{g} / \mathrm{L}$ ) was shaken with $6 \mathrm{~L}$ of $\mathrm{CTAB}$ solution having concentration of $7500 \mathrm{mg} / \mathrm{L}$ for $2 \mathrm{~h}$. After shaking, the supernatant was discarded and the SGW was washed thoroughly initially with tap water and finally with distilled water and then dried at $60^{\circ} \mathrm{C}$ for $24 \mathrm{~h}$. The SGW was thus converted to SMSGW and was used as an adsorbent for 2,4-D removal from wastewater.

\section{Analytical Method}

$\mathrm{MB}$ was measured in the concentration range of $0-12 \mathrm{mg} / \mathrm{L}$ by spectrophotometric method at a wavelength of $663 \mathrm{~nm}$ at neutral $\mathrm{pH}$. The relationship between absorbance and concentration was found as Absorbance $=0.1539 \times$ Concentration $(\mathrm{mg} / \mathrm{l})+0.0785\left(R^{2}=0.9961\right)$.

\section{Experimental Studies}

The batch experiments were carried out at room temperature $\left(30 \pm 2^{\circ} \mathrm{C}\right)$ using synthetic samples of MB prepared in distilled water and synthetic wastewater. $\mathrm{pH}$, alkalinity, chloride and conductivity of the synthetic wastewater were 7.4 $\pm 0.1,640$ $\mathrm{mg} / \mathrm{L}$ as $\mathrm{CaCO}_{3}, 600 \mathrm{mg} / \mathrm{L}$ as $\mathrm{Cl}^{-}$and $2400 \mu$ siemens $/ \mathrm{cm}$ respectively. The batch study was conducted at an agitation speed of $140 \mathrm{rpm}$ in a mechanical shaker with an initial MB concentration of $100 \mathrm{mg} / \mathrm{L}$. The sorption equilibrium contact time was found out with an adsorbent dose of $8 \mathrm{~g} / \mathrm{L}$. The shaking time was varied from 0 to 75 minutes. Experiments were carried out to see the effects of adsorbent doses which were varied in the range of 0 to $12 \mathrm{~g} / \mathrm{L}$ and with a contact time of 45 minutes. Experiments were carried out to see the effects of different interfering substances sodium chloride (0 to 200 $\mathrm{mg} / \mathrm{L}$ of $\mathrm{Cl}^{-}$), sodium sulfate (0 to $200 \mathrm{mg} / \mathrm{L} \mathrm{SO}{ }_{4}{ }^{2-}$ ) and $\mathrm{pH}$ (2.5-12). The adsorbent dose was $2 \mathrm{~g} / \mathrm{L}$ in all these cases. Effect of operating conditions like, temperature and shaking speed were studied in the range of $25^{\circ} \mathrm{C}$ to $35^{\circ} \mathrm{C}$ and 70 to 140 rpm respectively with the adsorbent dose of $2 \mathrm{~g} / \mathrm{L}$.

The performance of SMSGW for MB removal was also tested using MB spiked synthetic wastewater. For this case, the adsorbent dose was varied from 0 to $12 \mathrm{~g} / \mathrm{L}$, initial $\mathrm{MB}$ concentration was $100 \mathrm{mg} / \mathrm{l}$ and shaking time was 45 minutes. The kinetics study was also carried out to find out the equilibrium contact time. For this study the adsorbent dose was kept fixed at $8 \mathrm{~g} / \mathrm{L}$ and the shaking time was varied from 0 to 75 minutes.
The $\mathrm{pH}$ of the solution in all the above experiments (except the study on effect of $\mathrm{pH}$ ) was fixed at $7 \pm 0.1$ for distilled water spiked samples and $7.4 \pm 0.1$ for synthetic wastewater.

Fixed bed column studies for uptake of MB by SMSGW were conducted using columns having $2.5 \mathrm{~cm}$ internal diameter and $100 \mathrm{~cm}$ length. The column was packed with SMSGW between two supporting layers of glass wool. The bed depth was taken as $7.5 \mathrm{~cm}$. The column was charged with distilled water spiked MB solution in the up flow mode with a volumetric flow rate of $7.5 \mathrm{~mL} / \mathrm{min}\left(\sim 0.91 \mathrm{~m}^{3} / \mathrm{m}^{2} / \mathrm{hr}\right)$. The feeding concentration of MB was $100 \mathrm{mg} / \mathrm{L}$. The samples were collected at certain time intervals and were analysed for remaining $\mathrm{MB}$ concentration. In this case the temperature and $\mathrm{pH}$ were $30 \pm 2^{\circ} \mathrm{C}$ and $7 \pm 0.1$ respectively.

\section{Results and Discussion}

\section{A. Batch Study}

Kinetics study was conducted to find out the equilibrium contact time for MB uptake by SMSGW. The shaking time was varied from 0 to 75 minutes. It was noticed from Figure 1 that the reaction was very fast initially $(\sim 60 \%$ removal in first 15 minutes). Then it slowly increased and attained $92 \%$ and $94 \%$ in 45 and 75 minutes respectively. Thus, a contact time of 45 minutes would be sufficient to attain the equilibrium.

Experiments were also carried out to check the effectiveness of SMSGW in removing MB from synthetic wastewater samples. The MB concentration was $100 \mathrm{mg} / \mathrm{L}$. In this case, the equilibrium time was also observed to be 45 minutes, but the removal efficiency was slightly higher ( 97\%) than distilled water spiked samples since the wastewater contains various ions that increased the capacity (Fig. 1). The reason behind this might be due to weak intermolecular forces (e.g., hydrogen bonds) between MB and water in the wastewater system that were easily disrupted by the different ions present in the wastewater and forced MB molecules to be solubilized within the surfactant coating of CS on silica gel. This is analogous to the 'salting-out' of proteins from water containing salts at a high concentration. Also the increased removal might be due to slightly higher $\mathrm{pH}$ of wastewater.

Reaction kinetics data for the removal of MB by SMSGW were analyzed using four reaction models viz., first order, second order, pseudo-first order and pseudo second order reaction models. The equations and values of determining coefficients $\left(R^{2}\right)$ of the linear fit lines for first order, pseudofirst order, second order and pseudo-second order reaction models were shown in Table I. From the $R^{2}$ values of the best fit linear lines, it was clear that the reaction followed the pseudo-second order kinetics best among the other models. The basic assumption of pseudo-second order reaction model is that the process following this model is based on chemical adsorption or chemisorption [9]. Our observations suggested that rate-limiting step for the MB uptake by SMSGW was chemisorption. The value of reaction constant was found to be 
Proc. of the Fourth International Conference on Advances in Civil, Structural and Environmental Engineering - ACSEE 2016. Copyright $\odot$ Institute of Research Engineers and Doctors. All rights reserved.

ISBN: 978-1-63248-114-6 doi: 10.15224/ 978-1-63248-114-6-12

0.0043 and $0.05 \mathrm{~g} / \mathrm{mg}$-min for MB-spiked distilled water and wastewater respectively. The reaction constant for wastewater was higher than that for distilled water, which indicated that the reaction was faster for wastewater than distilled water. The reaction constant, so found, could be used for the design of different types of batch reactors generally used in the field.

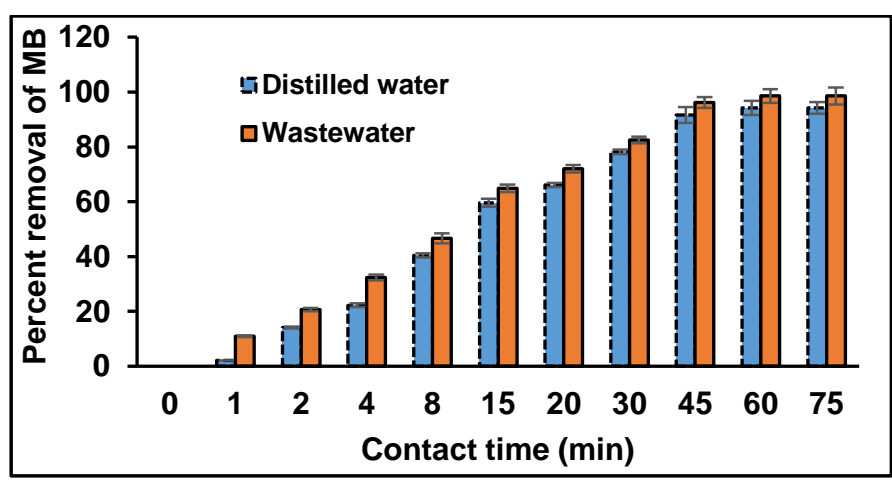

Fig. 1: Uptake of MB by SMSGW with respect to time

TABLE I

Equations and $R^{2}$ Values of the Linear Fit Lines of Kinetics Models for MB Removal by SMSGW

\begin{tabular}{|l|l|l|l|}
\hline Model & Sample & Equation of linear fit line & $R^{2}$ \\
\hline $\begin{array}{l}\text { First order } \\
\text { kinetic } \\
\text { model }\end{array}$ & Distilled water & $\ln \mathrm{C}_{\mathrm{t}}=4.5144-0.0448 \mathrm{t}$ & 0.9644 \\
\cline { 2 - 4 } $\begin{array}{l}\text { Pseudo-first } \\
\text { order kinetic } \\
\text { model }\end{array}$ & Wastewater & $\ln \mathrm{C}_{\mathrm{t}}=4.6107-0.0658 \mathrm{t}$ & 0.9596 \\
\cline { 2 - 5 } & Wastewater & $\ln \left(\mathrm{q}_{1}-\mathrm{q}_{\mathrm{t}}\right)=2.4005-0.0515 \mathrm{t}$ & 0.9834 \\
\hline $\begin{array}{l}\text { Second order } \\
\text { kinetic } \\
\text { model }\end{array}$ & Distilled water & $\left.1 / \mathrm{q}_{\mathrm{t}}+\mathrm{q}_{\mathrm{t}}\right)=2.398-0.006=0.0029 \mathrm{t}$ & 0.9324 \\
\cline { 2 - 5 } & Wastewater & $1 / \mathrm{C}_{\mathrm{t}}+0.0785=0.01169 \mathrm{t}$ & 0.8868 \\
\hline $\begin{array}{l}\text { Pseudo- } \\
\text { second order } \\
\text { kinetic }\end{array}$ & $\begin{array}{l}\text { Distilled water } \\
\text { model }\end{array}$ & $\mathrm{t} / \mathrm{q}_{\mathrm{t}}=1.0735+0.0628 \mathrm{t}$ & 0.9901 \\
\cline { 2 - 5 } & Wastewater & $\mathrm{t} / \mathrm{q}_{\mathrm{t}}=0.9226+0.0674 \mathrm{t}$ & 0.9900 \\
\hline
\end{tabular}

Since the adsorbent dose has significant effect on the removal process, the effect of this parameter was studied. The optimum adsorbent dose was found to be $8 \mathrm{~g} / \mathrm{L}$ for both distilled water spiked and wastewater samples. At the optimum condition, the removal efficiency for distilled water spiked and wastewater samples were $92 \%$ and $97 \%$ respectively (Fig. 2). The experiment was also carried out in order to find the effectiveness of silica gel waste (untreated) and the same was observed to be $6 \%$ only with a dose of $8 \mathrm{~g} / \mathrm{L}$ in a contact period of 45 minutes.

The results of the adsorbent dose study were used for the isotherm analysis. The adsorption isotherm defines the equilibrium state of the process. Several models have been developed to define the adsorption isotherm. Among them Langmuir isotherm model and Freundlich isotherm model were used in the present study. It was found that the experimental data fitted better for Langmuir model compared to Freundlich isotherm (Fig. 3) as compared from their $R^{2}$ values. The values of the constants for both the models were calculated and shown in Table II. The adsorption capacity of SMSGW for the removal of $\mathrm{MB}$ was found to be $23.47 \mathrm{mg} / \mathrm{g}$.

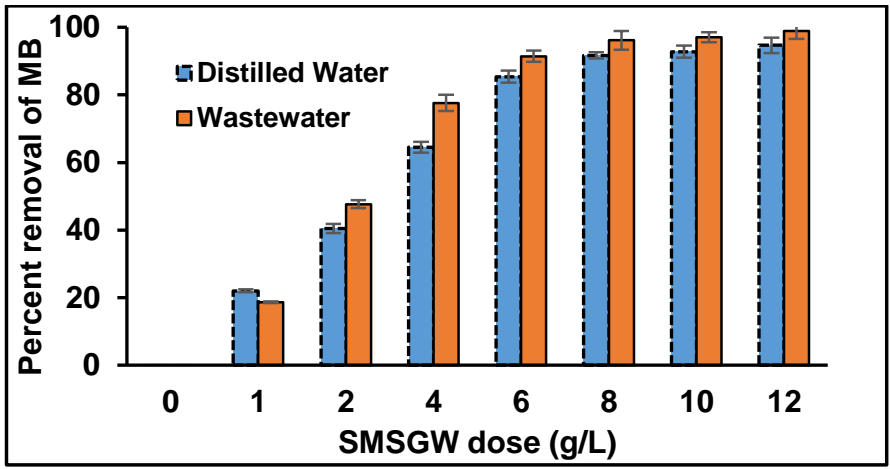

Fig. 2: Effect of adsorbent dose on uptake of MB by SMSGW

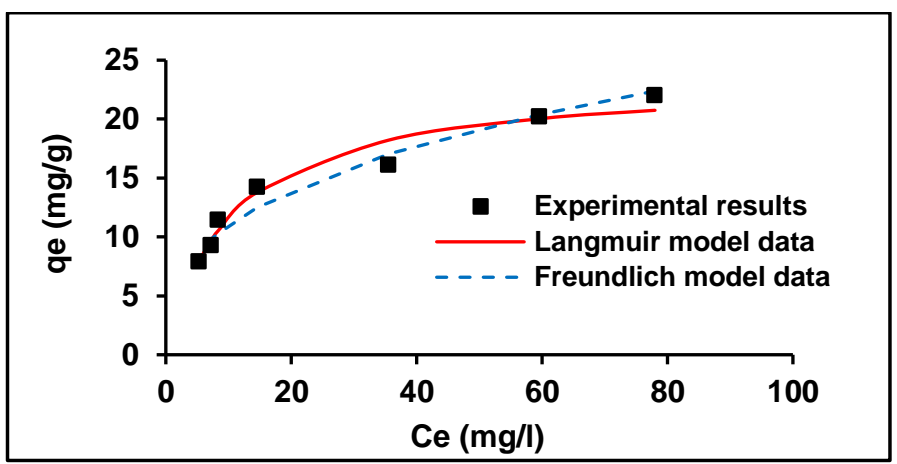

Fig. 3: Plots for Langmuir and Freundlich isotherm for MB removal by $\mathrm{SMSGW}$ at $30^{\circ} \mathrm{C}$

The effects of different salts like sodium chloride and sodium sulfate on MB uptake by SMSGW were studied. The effects of different ions on MB uptake by SMSGW were shown in Figure 4. In general the removal efficiency was unaffected by the presence of these salts in concentration range of 0 to $200 \mathrm{mg} / \mathrm{L}_{\text {of }} \mathrm{Cl}^{-}$and 0 to $200 \mathrm{mg} / \mathrm{L} \mathrm{SO}_{4}{ }^{2-}$.

The $\mathrm{pH}$ of an aqueous medium is an important factor that may influence the uptake of the adsorbate. The chemical characteristics of both adsorbate and adsorbent vary with $\mathrm{pH}$. It was thus important to study the effect of $\mathrm{pH}$ on the adsolubilization of MB into SMSGW. In batch study the $\mathrm{pH}$ was varied from 2.5 to 12 . The adsorbent dose was $2 \mathrm{~g} / \mathrm{L}$ and the initial MB concentration was $100 \mathrm{mg} / \mathrm{L}$. The contact time was 45 minutes. The plot of MB uptake by SMSGW at different $\mathrm{pH}$ is shown in Figure 5. Since, in lower $\mathrm{pH}$ desorption of CS from silica surface takes place, higher $\mathrm{pH}$ was favourable of adsolubilization of MB into SMSGW.

Temperature is an important operating condition for any separation process. Thus, removal of MB by SMSGW was studied at three different temperatures: $25^{\circ} \mathrm{C}, 30^{\circ} \mathrm{C}$ and $35^{\circ} \mathrm{C}$. It was found that the temperature in the range of $15-35^{\circ} \mathrm{C}$ had no effect on the MB uptake. 
Proc. of the Fourth International Conference on Advances in Civil, Structural and Environmental Engineering - ACSEE 2016. Copyright $\odot$ Institute of Research Engineers and Doctors. All rights reserved.

ISBN: 978-1-63248-114-6 doi: 10.15224/ 978-1-63248-114-6-12

The rate of shaking in batch study may have influence on the removal process. If the process is limited by film diffusion, then the increase in the shaking speed will increase the removal efficiency. So effect of shaking speed was studied in the range of 70 to $140 \mathrm{rpm}$. It was found that the shaking speed in the range of $70-140 \mathrm{rpm}$ had no effect on the removal process. Hence it could be stated that the film diffusion is not the rate limiting. It was also found that there was no leaching of surfactant from SMSGW at the shaking speed in the range of $70-140 \mathrm{rpm}$.

\section{TABLE II}

Constants of Langmuir and Freundlich isotherm model for the MB removal by SMSGW from distilled water spiked samples

\begin{tabular}{|c|c|c|}
\hline Model & Parameters & Values \\
\hline \multirow{3}{*}{$\begin{array}{l}\text { Langmuir } \\
\text { isotherm } \\
\text { model }\end{array}$} & Equation & $\begin{array}{c}1 / \mathrm{q}_{\mathrm{e}}=0.4369 / \mathrm{C}_{\mathrm{e}}+ \\
0.0426\end{array}$ \\
\hline & $\begin{array}{l}\text { Maximum adsorption } \\
\text { capacity, } q_{\max }(\mathrm{mg} / \mathrm{g}) \\
\text { Constant related to energy } \\
\text { of sorption system, } b\end{array}$ & $\begin{array}{l}23.47 \\
0.097\end{array}$ \\
\hline & $R^{2}$ & 0.9737 \\
\hline \multirow{4}{*}{$\begin{array}{l}\text { Freundlich } \\
\text { isotherm } \\
\text { model }\end{array}$} & Equation & $\begin{aligned} \ln \mathrm{q}_{\mathrm{e}} & =0.347 \ln \mathrm{C}_{\mathrm{e}} \\
& +1.5956\end{aligned}$ \\
\hline & $\begin{array}{l}\text { Freundlich constant related } \\
\text { to adsorption capacity, } k_{f} \\
{\left[(\mathrm{mg} / \mathrm{g})(\mathrm{L} / \mathrm{mg})^{1 / \mathrm{n}}\right]}\end{array}$ & 4.931 \\
\hline & Adsorption intensity, $1 / n$ & 0.347 \\
\hline & $R^{2}$ & 0.9485 \\
\hline
\end{tabular}

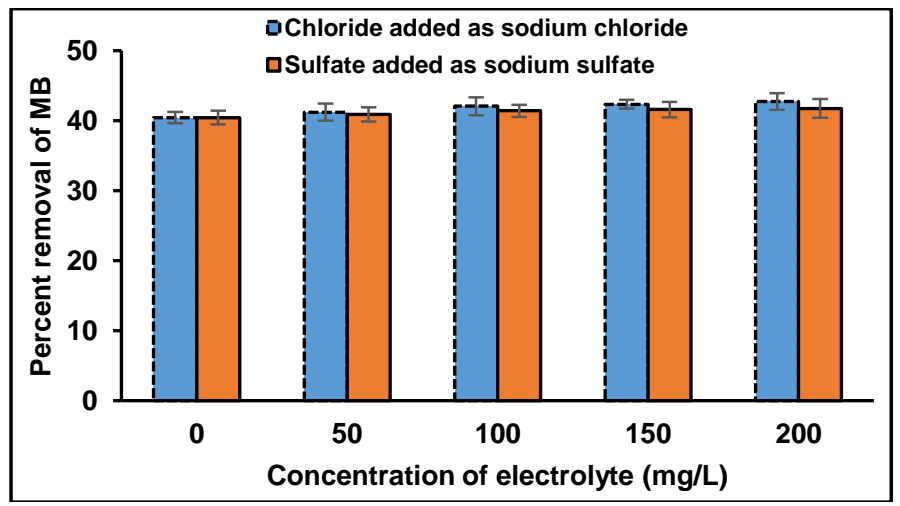

Fig. 4: Effect of chloride, sulfate and magnesium on MB uptake by SMSGW (SMSGW dose $=2 \mathrm{~g} / \mathrm{L}$, MB concentration $=100 \mathrm{mg} / \mathrm{L}, \mathrm{pH}=7 \pm 0.1$, Contact time $=45$ minutes $)$

\section{B. Batch Regeneration Study}

MB could be desorbed from exhausted silica surface using rectified spirit and acetone. It was observed that neither rectified spirit nor acetone desorbed CTAB from the exhausted SMSGW but they are capable to desorb MB. In this case, $2 \mathrm{~g}$ of exhausted SMSGW was shaken with $8 \mathrm{ml}$ of organic solvent (i.e. $250 \mathrm{~g} / \mathrm{L}$ ) for 60 minutes at a temperature of $30^{\circ} \mathrm{C}$. The regeneration efficiency was found to be $96 \%$ and $70 \%$ for rectified spirit and acetone respectively. The regenerated MB could be collected and reused further in the product manufacturing. The organic solvent could be distilled off using a Soxhlet apparatus and the same solvent could be recycled for further desorption. Regenerated SMSGW was again used for MB removal and was found to have the efficiency in the range of $82-85 \%$ (whereas the removal efficiency was $92 \%$ using fresh SMSGW). Hence, rectified spirit could be a better choice for regenerating exhausted SMSGW.

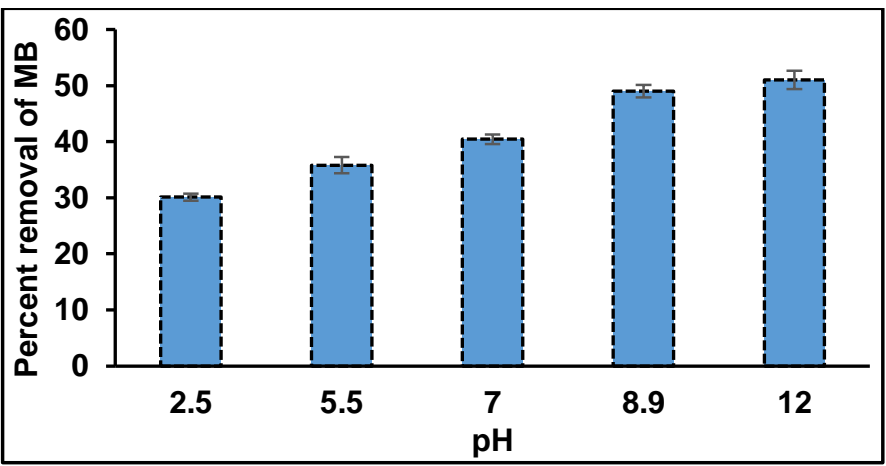

Fig. 5: Effect of $\mathrm{pH}$ on adsolubilization of MB into SMSGW $(\mathrm{SMSGW}$ dose $=2 \mathrm{~g} / \mathrm{L}, \mathrm{MB}$ concentration $=100 \mathrm{mg} / \mathrm{L}$, Contact time $=45$ minutes)

\section{Column Study}

\section{a. Behavior of adsorption column}

Fixed bed column study for MB removal from distilled water spiked sample by SMSGW was conducted. The depth of SMSGW was $7.5 \mathrm{~cm}$. The column was charged with MB spiked distilled water samples in the up flow mode with a volumetric flow rate of $7.5 \mathrm{~mL} / \mathrm{min}\left(\sim 0.91 \mathrm{~m}^{3} / \mathrm{m}^{2} / \mathrm{h}\right)$. The breakthrough curve for MB uptake using SMSGW was shown in Figure 6. The breakthrough time (corresponding to $\mathrm{C} / \mathrm{C}_{\mathrm{o}}=$ 0.01 ) and exhaust time (corresponding to $\mathrm{C} / \mathrm{C}_{\mathrm{o}}=0.9$ ) were found to be 14.75 and 17.75 hours respectively. The corresponding volumes of wastewater treated were 6.63 and $7.98 \mathrm{~L}$ respectively. The values of the important design parameters were calculated using the data from breakthrough curve. Height of adsorption zone was found to be $1.41 \mathrm{~cm}$ and the rate at which the adsorption zone was moving through the bed was $0.63 \mathrm{~cm} / \mathrm{h}$. The percentage of the total column saturated at breakthrough was found to be $88 \%$.

\section{a. Evaluation of column design parameters}

The fixed bed column was designed by Logit Model [10]. The linearized form of Logit equation can be written as:

$$
\ln \left[\frac{C}{C_{o}-C}\right]=-\frac{K N_{o} x}{V}+K C_{o} t
$$


Proc. of the Fourth International Conference on Advances in Civil, Structural and Environmental Engineering - ACSEE 2016. Copyright $\odot$ Institute of Research Engineers and Doctors. All rights reserved.

ISBN: 978-1-63248-114-6 doi: 10.15224/ 978-1-63248-114-6-12

Where,

$$
\begin{aligned}
& C=\text { solute concentration at any time } t \\
& C_{o}=\text { initial solute concentration }(100 \mathrm{mg} / \mathrm{L}) \\
& V=\text { approach velocity }(91 \mathrm{~cm} / \mathrm{h}) \\
& x=\text { bed depth }(7.5 \mathrm{~cm}) \\
& K=\text { adsorption rate constant }(\mathrm{L} / \mathrm{mg}-\mathrm{h}) \\
& N_{o}=\text { adsorption capacity constant }(\mathrm{mg} / \mathrm{L})
\end{aligned}
$$

Plot of $\ln \left[\frac{C}{C_{O}-C}\right]$ vs. $t$ gives a straight line with slope $K C_{o}$ and intercept $-\frac{K N_{o} x}{V}$ from which $K$ and $N_{o}$ could be calculated. Plot of $\ln \left[\frac{C}{C_{O}-C}\right]$ vs. $t$ was shown in Figure 7. The values of adsorption rate constant $(K)$ and adsorption capacity constant $\left(N_{o}\right)$ were obtained as $0.018063 \mathrm{~L} / \mathrm{mg} . \mathrm{h}$ and $20501 \mathrm{mg} / \mathrm{L}$ respectively. These values could be used for the design of adsorption columns. The adsorption capacity was found to be very high. Hence, it could be concluded that SMSGW is very efficient sorbent for MB uptake.

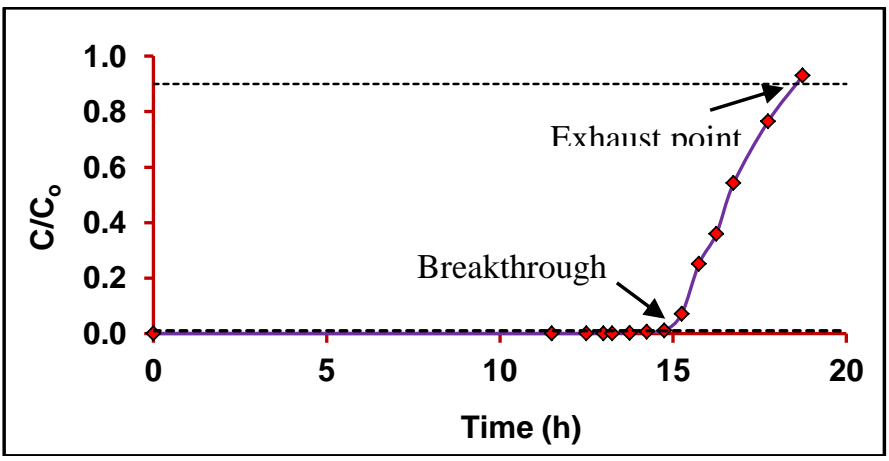

Fig. 6: Breakthrough curve for MB uptake by SMSGW

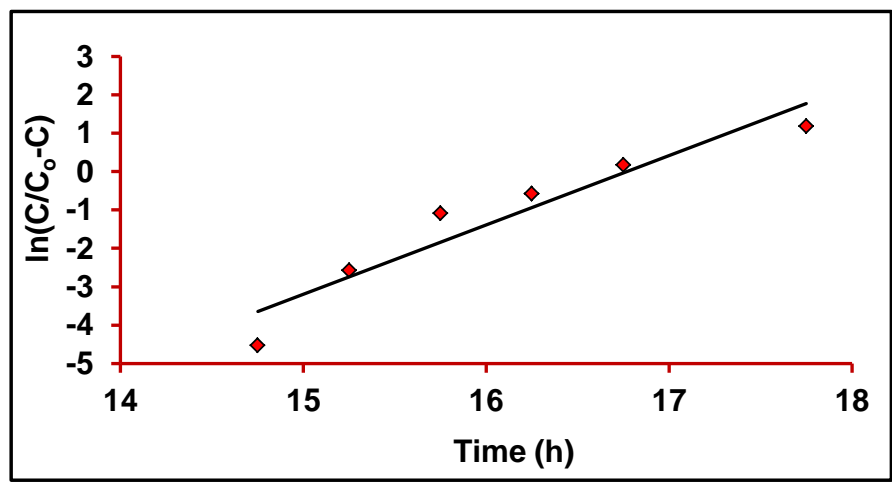

Fig. 7: Linearized form of logit model

\section{Conclusion}

SMSGW could effectively be used for removal of organic dye from dye bearing wastewater applying Adsolubilization process. The adsorption capacity of SMSGW was enhanced at elevated $\mathrm{pH}$. The Langmiur isotherm model was fitted better than Freundlich isotherm model. There was no significant effect of operating conditions on the process. The kinetics study revealed that the rate limiting step is the chemisorption. The adsorption capacity was found to be slightly higher for wastewater in comparison to distilled water spiked samples. After the removal of MB, the exhausted SMSGW was regenerated by rectified spirit and the MB could be collected and put it back in the industry for reuse. From column study, the values of adsorption rate constant $(K)$ and adsorption capacity constant $\left(N_{o}\right)$ were obtained as $0.018063 \mathrm{~L} / \mathrm{mg} . \mathrm{h}$ and $20501 \mathrm{mg} / \mathrm{L}$ respectively which established SMSGW an efficient candidate for removal of organic dye.

\section{References}

[1] Z. Wu, H. Zhong, X. Yuan, H. Wang, L. Wang, X. Chen, G. Zeng and $\mathrm{Y}$. Wu, "Adsorptive removal of methylene blue by rhamnolipidfunctionalized graphene oxide from wastewater," Water Research, vol. 67, pp. $330-344,2014$.

[2] H. Sun, S. Liu, S. Liu and S. Wang, "A comparative study of reduced graphene oxide modified $\mathrm{TiO}_{2}, \mathrm{ZnO}$ and $\mathrm{Ta}_{2} \mathrm{O}_{5}$ in visible light photocatalytic/photochemical oxidation of methylene blue," Applied Catalysis B: Environmental, vol. 146, pp. 162-168, March 2014.

[3] M.S. Mahmoud, J.Y. Farah and T.E. Farrag, "Enhanced removal of Methylene Blue by electrocoagulation using iron electrodes," Egyptian Journal of Petroleum, vol. 22, pp. 211-216, 2013.

[4] C.-H. Weng and V. Huang, Application of $\mathrm{Fe}^{\circ}$ aggregate in ultrasound enhanced advanced Fenton process for decolorization of methylene blue," Journal of Industrial and Engineering Chemistry, vol. 28, pp. 153-160, August 2015.

[5] S. Ledakowicz, M. Solecka and R.Zylla, "Biodegradation, decolourization and detoxification of textile wastewater enhanced by advanced oxidation processes," J. Biotech., vol. 89, pp. 175-184, 2001.

[6] K. Esumi and S.Yamamoto, "Adsorption of Sodium dodecyl sulfate on hydrotalcite and adsolubilization of 2-naphthol," Col. And Sur. A: Physicochem.1 \& Engg. Asp., vol. 137, pp. 385-388, 1998.

[7] P. M. Jain, J. S. Smith and K. T. Valsaraj, "Reusable adsorbent for dilute solution separation: sorption dynamics of phenanthrene on surfactant-modified alumina” Sep. Pur. Tech., vol. 17, pp. 21-30, 1999.

[8] T. Behrends and R. Herrmann, "Adsolubilization of anthracene on surfactant covered silica in dependence on $\mathrm{pH}$ : indications for different adsolubilization in admicelles and hemimicelles," Col. and Sur. A: Physicochem.l \& Engg. Asp., vol. 162, pp. 15-23, 2000.

[9] Y. S. Ho and G. Mckay, "Pseudo second order model for sorption process," Proc. Biochem., vol. 34, pp. 451, 1999.

[10] C. S. Oulman, "The logistic curve as a model for carbon bed design," J. AWWA, vol. 72, pp. 50-53, 1980.

\section{About Author (s):}

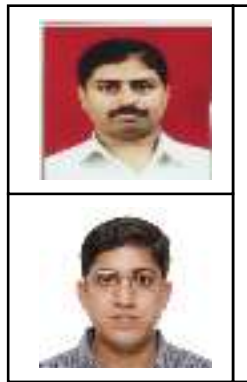

Dr. Suman Koner works on the adsorption and adsolubilization of organics using surfactant modified metal oxides. He also works on fluoride removal using nano-adsorbents.

Dr. Asok Adak works on adsorption, Adsolubilization of organics, advanced oxidation of emerging contaminants, and ecotoxicity of antibiotics. 